Tokura. Japanese 254 pp. ISBN

the Second Interin July, 1982, at of llie knowledge enzymology. The ing typed camcra ing European and te review of the

Ions dealing with itives, conformutnmobilisation on ects, and applicasolustry and are k. Bach paper is I with references of papers which chisive reference $\mathrm{cs}$, industrialists reference work chemical, bio We congratulate ssiul conference

han F. Kennedy harles A. White

\section{Single Crystals of Amylose with a Low Degree of Polymerization}

\author{
A. Buleon, F. Duprat \\ Centre de Recherche de Nantes (INRA), 44072 Nantes Cédex, France

\section{F.P. Booy* and H. Chanzy} \\ Centre de Recherche sur les Macromolécules Végétales (CNRS), $\uparrow$ \\ 53 X 38041 Grenoble Cédex, France
}

(Received: 28 February 1983)

\section{SUMMARY}

Single crystals of amylose with a low degree of polymerization were prepared from dilute solution in water or mixtures of water and ethanol. Depending on the concentration of ethanol used, three different polymorphs resulted. From pure water amylose $B$ was obtained and, respectively, from $15 \%(v / v)$ ethanol, amylose $A$, and from $40 \%(v / v)$ ethanol, $V$ amylose. The crystals were studied by electron diffraction after quenchfreezing and the crystallographic parameters were compared with those already reported in the literature.

\section{INTRODUCTION}

In revicwing the structure and morphology of crystalline polysacchitrides, the frequent occurrence of polymorphism for any given substance is striking. This is particularly the case with amylose, where fibre

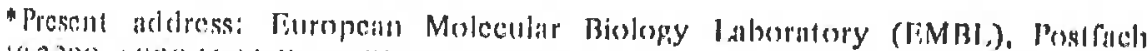
10.2209 , (1900 lleidelberg. West Ciermany.

† Associé à 1'Université Scientifique et Médicale de Grenoble.

161

Carbohydrate Polymers 0144-8617/84/\$03.00 - (C) Elsevier Applied Science Publishers Ltd, England, 1984. Printed in Great Britain 
diffraction analysis has revealed three different polymorphs called $A$, $B$ and V amylose (Katz \& Van Itallie, 1930; Sarko, 1974; French \& Murphy, 1977; Duprat et al., 1980; Sarko and Zugenmaier, 1980).

The A and B polymorphs are commonly found in native starches; llic A polymorph occurs frequently in cereal starches while the B poly. morph is largely found in tuber starches. A C polymorph intermediat: betwen $A$ and 13 is also found, typically in bean or root starches. The: $V$ polymorph is seldom encountered in nature (Senti, 1967). On the other hand, it is often found in recrystallized amyloses where it incompasses a family of crystalline structures which are characterized by helical amylose chains complexed with small molecules such as water, iodinc, alcohol or DMSO (Beill, 1942; Runclle \& lidwards, 14t3, Rundle, 1947; Zobel et al., 1967).

Each of the polymorphs of amylose has been examined with a view to determining the three-dimensional structure using X-ray fibrediffraction data. It is currently believed that the $\mathrm{V}$. crystals are com. posed of single helical amylose chains (Winter \& Sarko, 1974: Rappenecker \& Zugenmaier, 1981). For the A and B crystals, a double helical chain structure has been proposed (Wu \& Sarko, 1978a, b; Sarko \& Zugenmaier, 1980), but this has been questioned by other autlion who favour a single amylose helix for these two polymorphs (Brant, 1976; Cleven et al., 1978; Van den Berg, 1981). A further aspect of the crystallization behaviour of amylose is the formation of single crystals that are suitable for electron microscopy from dilute solution. Until now this behaviour has only been observed for $\mathrm{V}$ amylose but lias nevertheless led to an important series of morphological and crystallographic observations for amylose and its complexes (Saint John Manley, 1964; Yamashita, 1965; Yamashita \& Hirai, 1966; Bittiger \& Husemann, 1969; Yamashita \& Monobe, 1971; Yamashita et al., 1973; Booy et ul., 19.79).

Amylose can be crystallized from solution in the A and B forms but until now, in spite of numerous trials in different laboratories, it las not proved possible to obtain single crystals of the A and B poly. morphs. A crystallographic and morphological study of such crystils should prove invaluable in furthering the detailed knowledge of the structures of the $\mathrm{A}$ and $\mathrm{B}$ forms and their implications for the morntr ology and structure of starch. In fact the mechanism for the enzymic degradation of starch, and for its gelatinization : and lintnerization

would b scopy ar?

This single cr conditio inclualer iil (al) l: low desgl lion or ll

Preparati

Amylose starch as was dispe att $130^{\circ} \mathrm{C}$ clave was (15 ml) was main colloidal repeatedl. successive mounted microscol

Preparatic

Amylose supplied ( $5 \mathrm{ml}, \mathrm{O}$. C total solu ampoules erase any cooled to irom $6 \mathrm{~m}$ 
called $A$. Fronch of 501.

chos: Ihe

B poly-

renceliante

tics. "lhe

() () 114

ie it en-

rized hy

is water.

5. 1943:

in vicu

$y$ ribrete comt1974: (i)uble '; Sallko authors

(Brant, tof 110 zystals . Until nut has rstalloidnley. mann. cetal. ms hul it Mas polyystals if 114 itpliymic alion would be ideally studied with such single crystals by electron microscopy and other ultrastructural techniques.

This paper describes an approach to preparing and characterizing single crystals of the $A$ and $B$ polymorphs of amylose. Under certain conditions $\mathrm{V}$ amylose crystals were also obtained and these results are included. Following the general crystallization techniques developed in our laboratories, experiments were performed using amylose with a low degree of polymerization which was obtained either by fractionalion or by biosynthesis in vitro (Pfannemuller, 1968).

\section{EXPERIMENTAL}

\section{Preparation of single crystals of amylose $\mathbf{A}$}

Amylose with a $\overline{\mathrm{DP}}$ of 15 was obtained by mild hydrolysis of potato starch as described by Duprat et al. (1980). A suspension of this sample was dispersed in water $(\leqslant 1 \% \mathrm{w} / \mathrm{v})$ and heated inside a small autoclave at $130^{\circ} \mathrm{C}$ for $30 \mathrm{~min}$, after which the amylose had dissolved. The autoclave was allowed to $\mathrm{cool}$ and the solution was filtered. Pure ethanol $(15 \mathrm{ml})$ was then added to the clear filtrate $(85 \mathrm{ml})$ and the mixture was maintained at $60^{\circ} \mathrm{C}$ while crystallization occurred in the form of a colloidal precipitate. This was collected by centrifugation and washed repeatedly with a mixture of water and ethanol $(85 / 15 \mathrm{v} / \mathrm{v})$ by successive centrifugation. Drops of the crystals in suspension were then mounted conventionally on carbon-coated grids for electron microscopy.

\section{Preparation of single crystals of amylose B}

Amylose with a $\overline{\mathrm{DP}}$ of 35 obtained by biosynthesis in vitro was kindly supplied by $\mathrm{Dr}$ B. Pfannemuller. Batches of a dispersed suspension $(5 \mathrm{ml}, 0.05 \% \mathrm{w} / \mathrm{v})$ of this amylose were heated to $100^{\circ} \mathrm{C}$ where almost total solution occurred. These were then filtered into thick-walled glass ampoules which were sealed and maintained at $160^{\circ} \mathrm{C}$ for $15 \mathrm{~min}$ to erase any memory of previous crystal forms. The ampoules were then conled to $4^{\circ} \mathrm{C}$ and maintained at this temperature for poriods ranging from 6 months to 2 ycars. The amylose crystallized slowly in the form

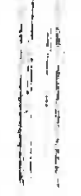


of a rather coarse precipitate. The ampoules were then heated slowly to $117^{\circ} \mathrm{C}$ and left at this temperature for $10 \mathrm{~min}$. Subsequently they werc cooled to room temperature and recrystallization occurred in 4-5 ditys. The ampoules were then opened and the precipitate was washed $r^{\circ-}$ peatedly by centrifugation and mounted on carbon-coated grids, is before, for electron microscopy.

\section{Preparation of single crystals of $\mathrm{V}$ amylose}

Amylose with a $\overline{\mathrm{DP}}$ of 35 was prepared by mild hydrolysis of wrinkled. pea starch using the method of Colonna et al. (1982) and $10 \mathrm{mg}$ of this were dissolved in $10 \mathrm{ml}$ of $4 \%(\mathrm{w} / \mathrm{v}) \mathrm{NaOH}$, filtered, and dialysed at room temperature against a mixture of water and ethanol $(60 / 40 \mathrm{v} / \mathrm{N}$. After 1 day a flocculent crystalline precipitate was present which was centrifuged and repeatedly washed in a $60 / 40 \mathrm{v} / \mathrm{v}$ mixture of water and ethanol. The crystals were then mounted as previously described for electron microscopy.

\section{Electron microscopy}

Transmission electron microscopy was carried out with a Philips EM $400 \mathrm{~T}$ electron microscope. For imaging, the prepared grids were first shadowed with a tungsten-tantalum alloy using a Balzers electron gun; micrographs were recorded at $80 \mathrm{kV}$. For diffraction, the prepard grids were first positioned for $24 \mathrm{~h}$ inside a desiccator where a relative humidity of $95 \%$ was maintained by a large excess of saturated zimi sulphate solution. Grids were then rapidly mounted in the specimin cooling holder, quench-frozen in liquid nitrogen and inserted into ths microscope and examined in the frozen, hydrated state (Booy "l al. 1979). Electron diffraction patterns were recorded at $120 \mathrm{kV}$ using minimal exposure techniques. For calibration purposes, some crystuts were also examined supported on a gold-coated carbon film.

\section{X-Ray diffraction}

X-ray powder diffraction was carried out with a CGR X-ray generuttu operating at $45 \mathrm{kV}$ and $30 \mathrm{~mA}$ equipped with a Guinier monochrom tor and a scintillation counter. When only a very small sample $\mathrm{H}_{2 \mathrm{~s}}$

aviailal, with th

A Amy

Crystals rectangl rosette-l and can

Fig. 1. (4 will lungs mividual 
wisilable either a holder specially designed for examining micro-samples with the counter outfit or a flat-film camera was used.

\section{RESULTS}

A Amylose crystals

Crystals of A amylose grow in a rosette-like fashion with an individual retangular platelet crystal forming a branch of the rosette. When the msette-like structures are disturbed, the platelet crystals are loosened and can be examined by transmission electron microscopy. Figure 1(A)

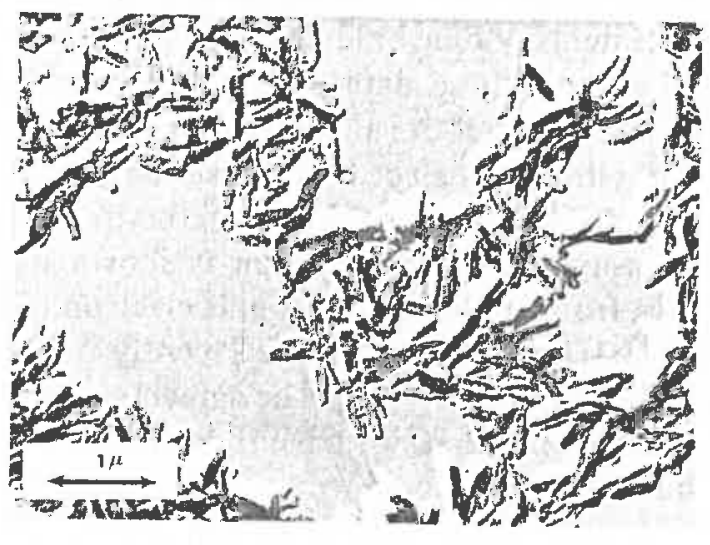

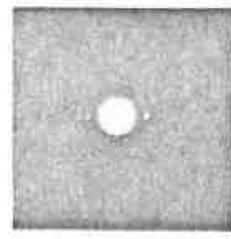

B

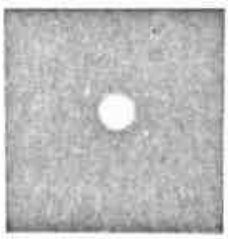

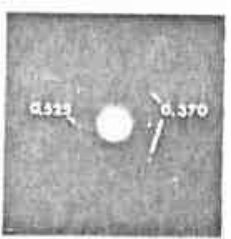

D

Fig. 1. (A) Transmission electron micrograph of A amylose crystals shadowed

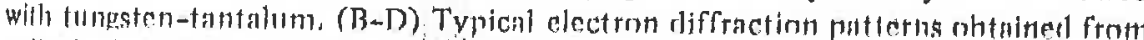

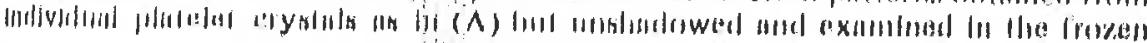


shows a preparation from the shaken crystals where quite thick

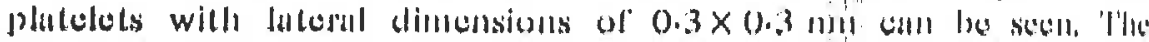
remarkable homogeneity of the crystals probably, results from the low polydispersity of the $\overline{\mathrm{DP}} 15$ amylose used.

Electron diffraction data are only obtained after quench-freezing and examination of the crystals in the frozen, hydrated state when sharp spots result. However, due to the random orientation of the crystals on the supporting film, a variety of diffraction patterns is recorded. This is illustrated in Figs 1(B)-(D) where the patterns most frequently obtained are shown. At first sight, these patterns seem un* correlated as they originate from tilted crystals. To clarify this it is necessary to tilt and rotate each crystal, sequentially recording the electron diffraction patterns (Chanzy et al., 1981). Unfortunately, because our specimen cooling holder has no rotation facility, we are not yet able to exploit these data and thus can neither establish the point group nor the unit cell. As an alternative, powder diffraction datu can be obtained either by electron diffraction (again in the frozen, hydrated state), or by conventional X-ray methods.

The trace of a typical X-ray diagram is shown in Fig. 2 and the principal spacings from both the X-ray and electron diffraction studies are listed in Table 1 together with some recently published X-ray dati for A amylose (Wu \& Sarko, 1978a). The agreement between the datal is quite good and confirms that we have indeed obtained single crystals of the A polymorph of amylose. We are unfortunately unable to confirm the symmetry and unit cell parameters that Wu \& Sarko derivid because of the limitations imposed by our specimen cooling holder.

\section{B Amylose crystals}

A typical sample of the B amylose preparation is shown in Fig. 3. It consists of a lamellar precipitate without any clearly defined gcometrical shape. Electron diffraction from this sample in the frozen hydrated state results in sharp hexagonal diffraction patterns as showil in the inset in Fig. 3. The pattern contains seven independent refletions which may be indexed as the (hk0) plane of a hexagonal system with $a=b=1.8 \mathrm{~nm}$ and $\gamma=120^{\circ}$.

Table 2 compares the data from the pattern shown in the inset in Fig. 3 with the data for B amylose obtained from X-ray fibre-diffras: 
line 1. 111 ic lin

हर्माn Whe'n it the is $11 \%$ thes i11 11110 is ill is II $1111^{\circ}$ 110\%, $\therefore$ : i) 1110 iliti: nern.

the athes d:Ital this is sials (a) सखथ।

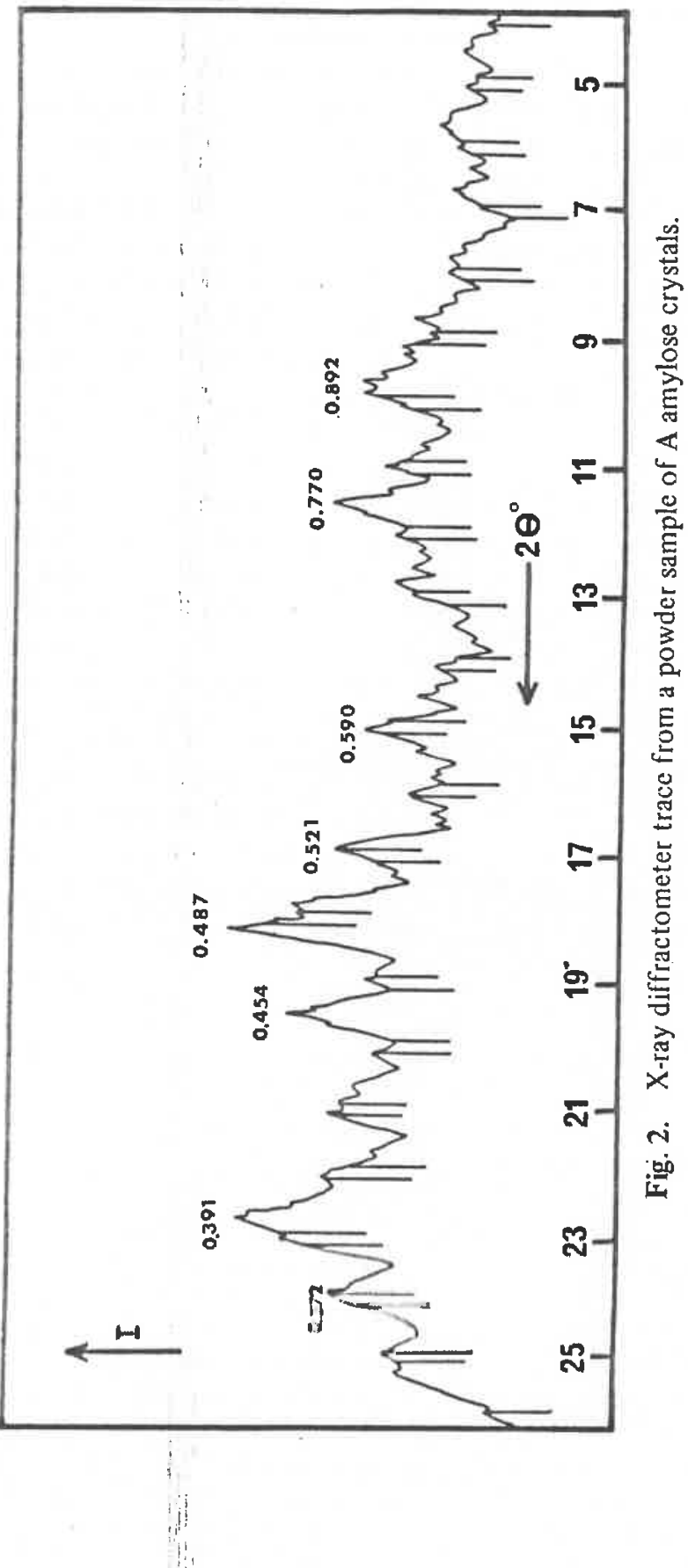


TABLE 1

A Ainyluase Cryatalit

\begin{tabular}{|c|c|c|c|c|c|}
\hline \multicolumn{2}{|c|}{$\begin{array}{c}X \text {-ray powder diagram } \\
\text { (this study) }\end{array}$} & \multirow{2}{*}{$\begin{array}{l}\text { Electron diffraction } \\
\text { powder diagram } \\
\text { (this study)d } \\
\text { spacings in } \mathrm{nm}\end{array}$} & \multicolumn{3}{|c|}{$\begin{array}{c}\text { X-ray analysis } \\
\text { (Wu \& Sarko, 1978a) }\end{array}$} \\
\hline $\begin{array}{l}\text { d spacings } \\
\text { in } \mathrm{nm}\end{array}$ & Intensity $^{a}$ & & $\begin{array}{l}d \text { spacings } \\
\text { in } \mathrm{nm}\end{array}$ & $\begin{array}{l}\text { Miller indices } \\
\qquad(h k l)\end{array}$ & Intensity ${ }^{a}$ \\
\hline 0.892 & M & & $\begin{array}{l}0.888 \\
0.786\end{array}$ & $\begin{array}{l}020 \\
101\end{array}$ & $\begin{array}{l}M \\
M\end{array}$ \\
\hline 0.770 & $\mathrm{M}$ & $0.680^{b}$ & & & \\
\hline 0.590 & M & 0.590 & 0.589 & 030 & $S$ \\
\hline 0.521 & M & 0.525 & 0.520 & 201 & $S$ \\
\hline 0.487 & $S$ & & 0.487 & $220(211)$ & $S$ \\
\hline 0.454 & M & 0.446 & 0.446 & 040 & W \\
\hline 0.391 & $S$ & 0.386 & 0.389 & 231 & $\mathrm{~S}$ \\
\hline 0.372 & $\mathrm{M}$ & 0.372 & 0.372 & $310(132)$ & S \\
\hline
\end{tabular}

${ }^{a} \mathrm{~S}=$ strong; $\mathrm{M}=$ medium; $\mathrm{W}=$ weak.

$\dot{b}$ Probably originates from traces of $\mathrm{V}$ amylose.

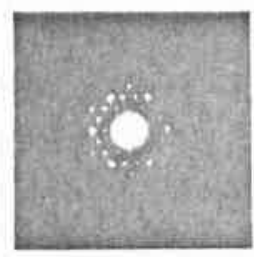

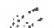

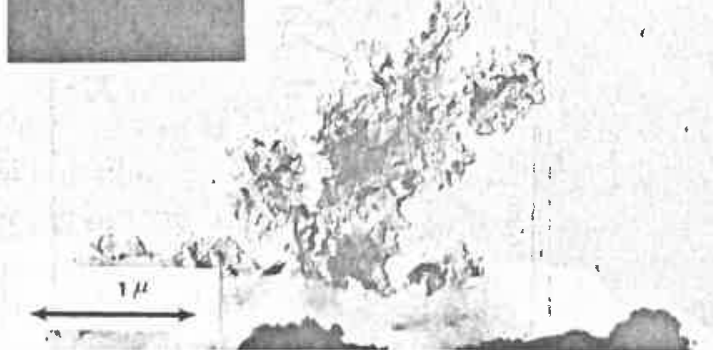

Fig. 3. Transmission electron micrograph of B amylose crystals shadowed wilh tungsten-tantalum; in the upper left corner typical electron diffraction pattern obtained from fragments of crystals unshadowed and examined in the frozen hydrated state.

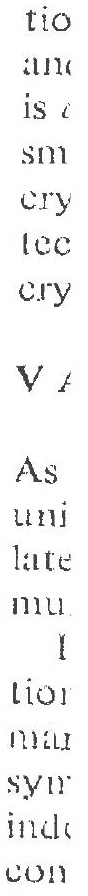


TABLE 2

B Amylose Crystals

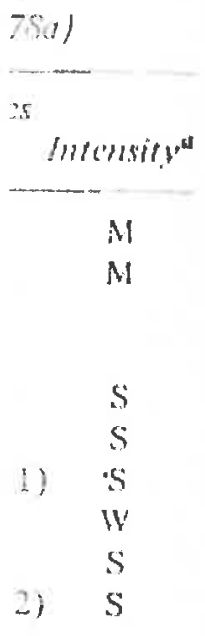

\begin{tabular}{|c|c|c|c|c|}
\hline \multicolumn{2}{|c|}{$\begin{array}{l}\text { Electron diffraction } \\
\text { diagram (this work) }\end{array}$} & \multicolumn{3}{|c|}{$\begin{array}{c}\text { X-ray analysis } \\
(W u \text { \& Sarko, 1978b) }\end{array}$} \\
\hline $\begin{array}{l}\text { dspacings in } \\
n m\end{array}$ & $\begin{array}{l}\text { Relative } \\
\text { intensity }^{a}\end{array}$ & $\begin{array}{c}d \text { spacings in } \\
\mathrm{nm}\end{array}$ & $\begin{array}{l}\text { Relative } \\
\text { intensity }^{a}\end{array}$ & $\begin{array}{c}\text { Miller } \\
\text { indices }(h k l)\end{array}$ \\
\hline 1.560 & $M$ & 1.614 & $\mathrm{M}$ & 100 \\
\hline 0.780 & $M$ & 0.797 & M & 200 \\
\hline 0.589 & M & 0.600 & $\mathrm{M}$ & 120 \\
\hline 0.520 & $S$ & 0.534 & $\mathrm{~S}$ & 300 \\
\hline 0.447 & $\mathrm{M}$ & 0.459 & $S$ & 220 \\
\hline 0.337 & $M$ & 0.347 & $\mathrm{M}$ & 140 \\
\hline 0.263 & $\mathrm{M}$ & 0.269 & $\mathrm{M}$ & 600 \\
\hline
\end{tabular}

' $\mathrm{S}=$ strong; $\mathrm{M}=$ medium.

tion by $\mathrm{Wu} \&$ Sarko (1978b). The agreement between the intensities and the $d$-spacings is quite good, although the unit cell size in this study is $a=b=1.8 \mathrm{~nm}$ compared with $1.85 \mathrm{~nm}$ in Wu \& Sarko's study. This small difference probably results from the fact that in our study the crystals may not have been fully hydrated in spite of the freezing technique employed. However, we can conclude with certainty that the crystals presented in Fig. 3 are indeed of the B polymorph of amylose.

V Amylose crystals

As shown in Fig. 4(A), the $\mathrm{V}$ amylose crystals prepared here have a uniform and clear morphology and consist of individual platelets with lateral dimensions of about $1 \mu \mathrm{m}$ that thicken by the formation of multiple screw dislocations.

In the frozen hydrated state each crystal gives a well-defined diffraction pattern. Figure $4(C)$ is an example emanating from the region marked by a circle in Fig. 4(B). The pattern again has hexagonal symmetry and may be indexed with $a=b=1.37 \mathrm{~nm}$; it may also be indexed in terms of the larger orthorhombic unit cell that is normally comsiclaresl for $\mathrm{V}$ amylose with $a=1.37 \mathrm{~nm}, h=2.37 \mathrm{~nm}$ and $\gamma=90^{\circ}$. 


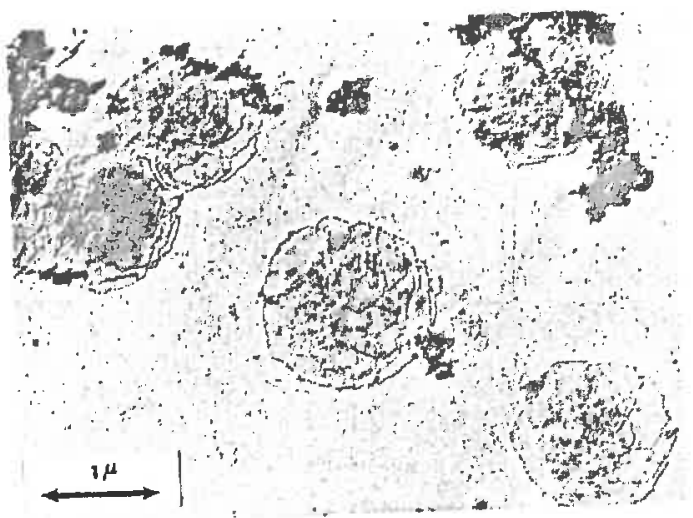

A
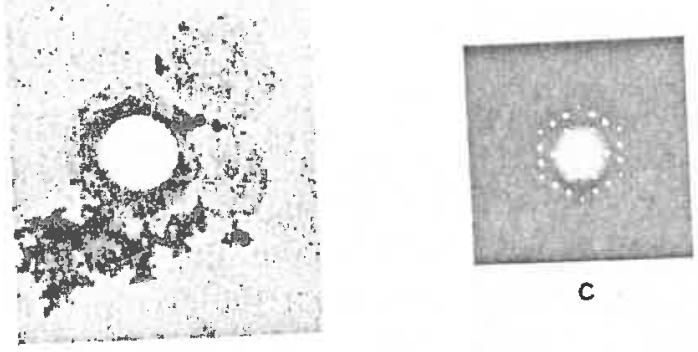

c

Fig. 4. (A) Transmission electron micrograph of $V$ amylose crystals shadowed with tungsten-tantalum. (B) Transmission electron micrograph of a cluster of unshadowed $\mathrm{V}$ amylose crystals in a frozen hydrated state. (C) Electron diffraction pattern (correctly oriented) recorded from the circled area of Fig, 4(B).

$$
\therefore
$$

The results are listed in Table 3 and compared with the X-ray data of Zobel et al. (1967). The agreement is excellent and demonstrates thut the crystals presented here are of the $V_{\mathrm{H}}$ type that is already will documented in the literature.

\section{DISCUSSION}

The results presented here illustrate clearly the diverse nature of amylose in crystallizing from dilute solution. By merely modifying the 
TABLE 3

V Amylose Crystals

\begin{tabular}{cccccc}
\hline \multicolumn{2}{c}{$\begin{array}{c}\text { Electron diffraction } \\
\text { diagram (this work) }\end{array}$} & & \multicolumn{3}{c}{$\begin{array}{c}\text { X-ray analysis } \\
\text { (Zobel et al., 1967) }\end{array}$} \\
\cline { 1 - 4 } $\begin{array}{c}\text { dspacings in } \\
n m\end{array}$ & $\begin{array}{c}\text { Relative } \\
\text { intensity }\end{array}$ & & $\begin{array}{c}\text { d spacings in } \\
n m\end{array}$ & $\begin{array}{c}\text { Relative } \\
\text { intensity }\end{array}$ & $\begin{array}{c}\text { Miller } \\
\text { indices (hkl) }\end{array}$ \\
\cline { 4 - 6 } 1.181 & $\mathrm{M}$ & & 1.185 & $\mathrm{~S}$ & 110 \\
0.684 & $\mathrm{~S}$ & & 0.683 & $\mathrm{VS}$ & 200 \\
0.446 & $\mathrm{~S}$ & & 0.448 & $\mathrm{VS}$ & 240 \\
0.392 & $\mathrm{M}$ & & 0.393 & $\mathrm{M}$ & 060 \\
0.326 & $\mathrm{M}$ & 0.326 & $\mathrm{~W}$ & 420 \\
\hline
\end{tabular}

V $\mathrm{VS}=$ very strong; $\mathrm{S}=$ strong; $\mathrm{M}=$ medium; $\mathrm{W}=$ weak.

proportions of water and ethanol in the mother liquor one of three different crystalline polymorphs may be obtained. From pure water the B polymorph is obtained, while with only a small proportion of ethanol." the A polymorph results. When the proportion of ethanol is increased to roughly $50 \%$ the $\mathrm{V}$ polymorph is obtained.

Even though water and ethanol are listed as poor solvents or even. precipitants for amylose, small changes in their relative concentrations must induce modifications in the conformation adopted by the amylose molecules in solution. This is witnessed by the three different types of crystal which can be grown when the alcohol percentage of the crystallization solution is increased. A substantial amount of ethanol stabilizes single helices of amylose which crystallize accordingly in the mono-helical V form. On the other hand, with solutions where water is either the dominant or the only solvent the two conformations leading to $A$ and $B$ amylose are stabilized. In these two cases our present data

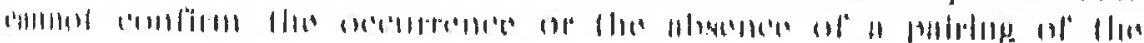

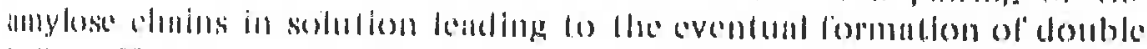
helices. The evidence of such pairing, which could be investigated by classical solution techniques (such as NMR and viscometry), is important to gain an understanding of the structure of native starch granules which occur in either the A or the B form depending on their origin. In the light of the data presented here it would also be most interesting to compare the conditions of biosynthesis to see whether 
native polymorphism is also due to compositional changes in the biocrystallization media during starch biosynthesis.

Of the three polymorphs, only the $\mathrm{V}$ amylose crystals behave as typical chain folded polymer single crystals. They can be prepared with any molecular weight amylose and always yield the same type of crystal $-10 \mathrm{~nm}$ thick hexagonal platelets where the planar faces have grown perpendicular to the helical amylose chain axis. Similar $\mathrm{V}$ amylose crystals have already been described by Yamashita et al. (1973), but the use of our freezing technique to obtain electron diffraction data enables us to assign them unambiguously to the $V_{H}$ form of amylose. This implies that no ethanol is involved in the crystal structure and thus the hexagonal structure (in projection) is stabilized only by water molecules. With other alcohols such as $n$-butanol or iso-propanol it is probable that alcohol molecules are incorporated in the crystal lattice (Booy et al., 1979), and this leads to different crystal morphologies (Yamashita et al., 1973).

The preparation and characterization of single crystals of A and $B$ amylose are presented here for the first time. Previous attempts to obtain B amylose crystals had given only a polycrystalline precipitate (Pfannemuller \& Bauercarnap, 1977). Our success is certainly due to the use of fractions of amylose with a low degree of polymerization. In that case, the crystals are made of short molecular stems and the crystallization does not require a chain-folding mechanism.

Both the A and B polymorphs are found in native starch granules. Until now, the native granules have been studied only by X-ray diffraction and, with one exception (Kreger, 1951), only by powder methods. The present work shows that with the electron microscope oriented diffraction data may be obtained from micron-sized crystals of amylose. A logical extension of this work is to investigate native starch granules by electron diffraction using ultra-thin sections or fragmented starch granules. Such work is currently in progress in our laboratories.

\section{ACKNOWLEDGEMENT}

The authors wish to thank Mr R. Vuong for his help with the electron microscopy. 


\section{REFERENCES}

But, R. S. (1942). J. Am. Chem. Soc., 64, 1388.

Vitiger, H. \& Husemann, E. (1969). Koll Zeitschrift Z. Polymere, 232, 43.

Awy, F. P., Chanzy, H. D. \& Sarko, A. (1979). Biopolymers, 18, 351.

B!nt, D. A. (1976). Quart. Rev. Biophys., 9, 527.

Chsmy, H. D., Excoffier, G. \& Guizard, C. (1981). Carbohydrate Polymers, 1, 67.

(Kven, R., Van den Berg, C. \& Van der Plas, L. (1978). Starke, 30, 223.

Colunna, P., Buleon, A., Lemaguer, M. \& Mercier, C. (1982). Carbohydrate rolymers, 2,43 .

Duprat, F., Gallant, D., Guilbot, A., Mercier, C. \& Robin, J. P. (1980). In: Les Polymères Végétaux, ed. B. Monties, Gauthier-Villars, Paris, p. 176.

French, A. D. \& Murphy, V. G. (1977). Cereal Foods World, 22, 61.

Kal?, J. R. \& Van Itallie, T. B. (1930). Z. Physik. Chem. A, 150, 90.

Kicker, D. R. (1951). Biochem. Biophys. Acta, 6, 406.

Risnnemuller, B. (1968). Die Stärke, 11, 351.

Pisnnemuller, B. \& Bauercarnap, A. (1977). Colloid and Polymer Sci., 255, 844.

Rappenccker, G. \& Zugenmaier, P. (1981). Carbohydr. Research, 89, 11.

Rundle, R. E. (1947). J. Amer. Chem. Soc., 69, 1769.

Rundle, R. E. \& Edwards, F. C. (1943). J. Amer. Chem. Soc., 65, 2200.

Sint John Manley, R. (1964). J. Polym. Sci., A2, 9503.

Sarkn, A. (1974). In: Structure of fibrous biopolymers, Colston Paper no. 26, cis E. D. T. Atkins and A. Keller, Butterworths, London, p. 335.

Sisko, A. \& Zugenmaier, P. (1980). In: Fiber diffraction methods, eds A. D. Frcnch and K. C. Gardner, ACS symposium series, 141, p. 459.

Senti, F. R. (1967). In: Starch chemistry and technology, eds R. L. Whistler and E. F. Paschall, Academic Press, New York, Vol. II, p. 511.

Van den Berg, C. (1981). Vapour sorption equilibrium and other water-starch interactions: a physico-chemical approach, PhD Dissertation, Wageningen.

Hinter, W. T. \& Sarko, A. (1974). Biopolymers, 13, 1447.

Niu, H. H. \& Sarko, A. (1978a). Carbohydr. Research, 61, 7.

Hi, I. H. \& Sarko, A. (1978b). Carbohydr. Research, 61, 27.

Yanashita, Y. (1965). J. Polym. Sci., A3, 3251.

Yamashita, Y. \& Hirai, N. (1966). J. Polym. Sci., A.2, 4, 161.

Yamashita, Y.\& Monobe, K. (1971). J. Polym. Sci., A2, 9, 1471.

Yamashita, Y., Ryugo, J. \& Monobe, K. (1973). J. Electron Microscopy, 22, 19.

Zobcl, I., F., French, A. D. \& Hinkle, M. E. (1967). Biopolymers, 5, 837. 